\title{
$\mathrm{PH} 1000_{\text {actualidad }}$
}

\section{El Carnaval de Fuentes de Andalucía (Sevilla) estrena el programa Sintonizando Patrimonio}

\begin{abstract}
Sintonizando Patrimonio es un proyecto de valorización del patrimonio inmaterial de Andalucía impulsado por la Asociación Andaluza de Antropología (ASANA). Es una experiencia novedosa que aúna iniciación a la investigación para estudiantes y difusión para interesados en el patrimonio cultural andaluz. Los participantes en el programa tienen la posibilidad de poner en práctica las técnicas y métodos de la antropología a través de la observación y la participación en manifestaciones culturales. En marzo se hizo la primera salida con destino: el Carnaval de Fuentes de Andalucía. El resto de actividades programadas, que se extendían hasta septiembre de 2020, quedan sujetas al transcurso de la crisis del Covid-19. No obstante, esperamos que con el advenimiento de la normalidad el resto de salidas contempladas en Sintonizando Patrimonio puedan tener lugar y, con ello continuar con el proyecto.
\end{abstract}

Elvira Mora Lázaro, Carmen Gutiérrez Rebollo | Asociación Andaluza de Antropología (ASANA)

Url de la contribución <www.iaph.es/revistaph/index.php/revistaph/article/view/4646>

Sintonizando Patrimonio es un proyecto que trata, en primer lugar, de acercar a la comunidad científica, la sociedad civil y el alumnado a distintas manifestaciones culturales de Andalucía, mediante la asistencia a fiestas, rituales, eventos vinculados a oficios y saberes o expresiones orales y musicales. El proyecto aspira, además, a cumplir con una labor de documentación y divulgación científica del patrimonio inmaterial para promover la valoración de estas actividades tradicionales. Un tercer pilar de Sintonizando Patrimonio es la confluencia del trabajo con la práctica radiofónica: a través del podcast antropológico de RadiUs "Caleidoscopio", los archivos sonoros, los testimonios de campo y otro tipo de recursos obtenidos por los participantes, componen "paisajes sonoros" de las experiencias.

Este proyecto, programado de enero a septiembre de 2020, está organizado por la Asociación Andaluza de Antropología (ASANA), en colaboración con el Instituto Andaluz de Patrimonio Histórico y su proyecto Atlas del Patrimonio Inmaterial de Andalucía, el Departamento de Antropología Social de la Universidad de Sevilla y los integrantes del programa Caleidoscopio de RadiUS.

El pasado 1 de marzo tuvo lugar la primera salida al Carnaval de Fuentes de Andalucía, en Sevilla, referente etnológico con un notable valor histórico, que fue reco-

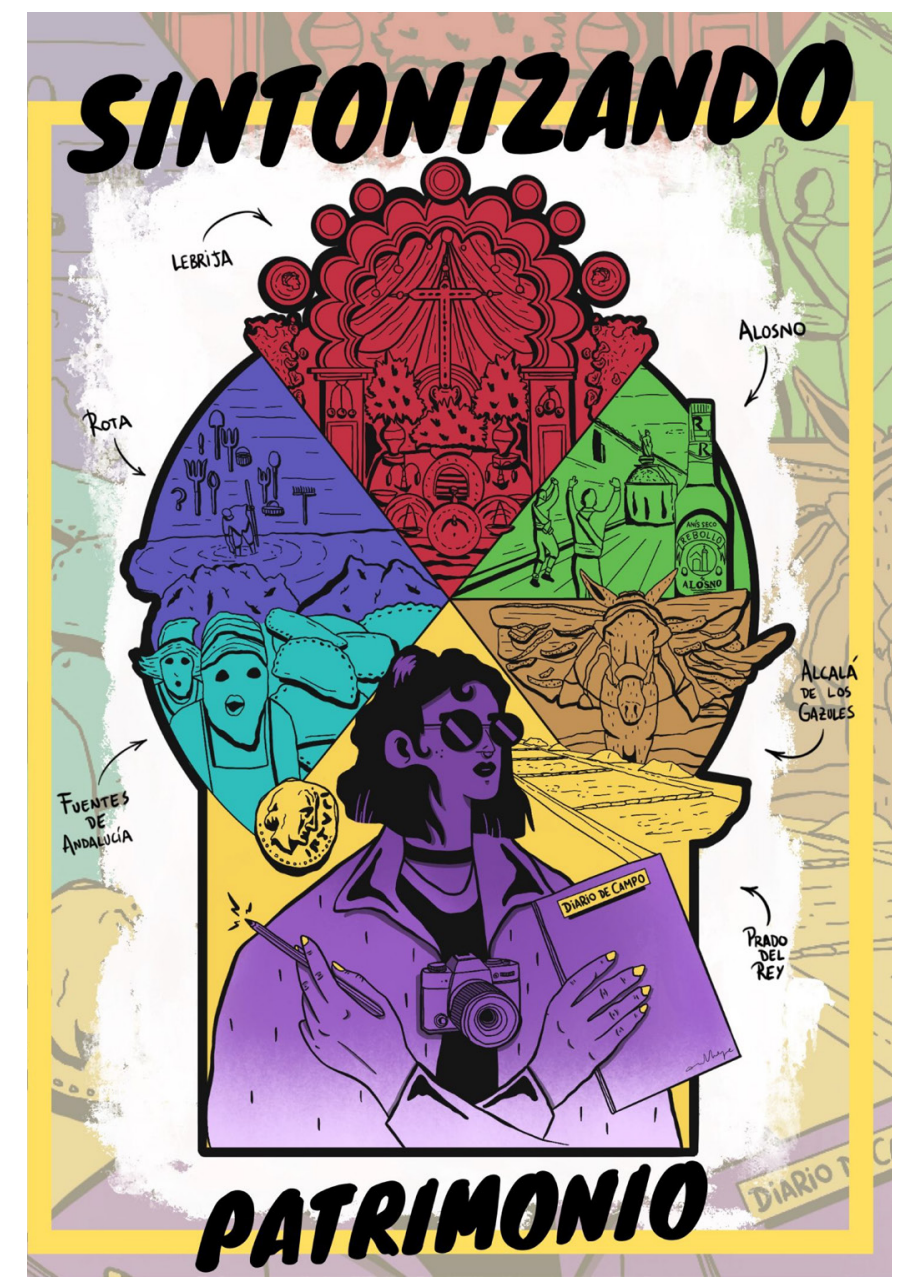




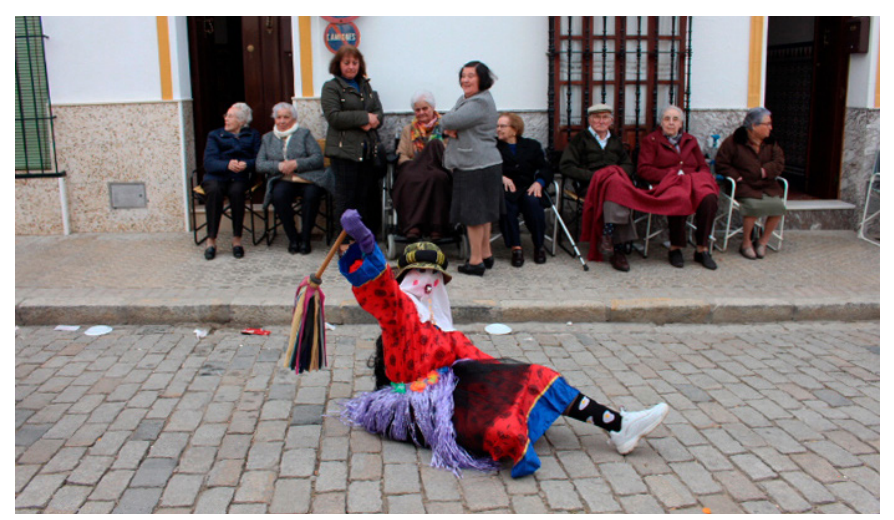

"Máscara" posando para (la cámara) delante de un grupo de ancianos en la calle Carrera

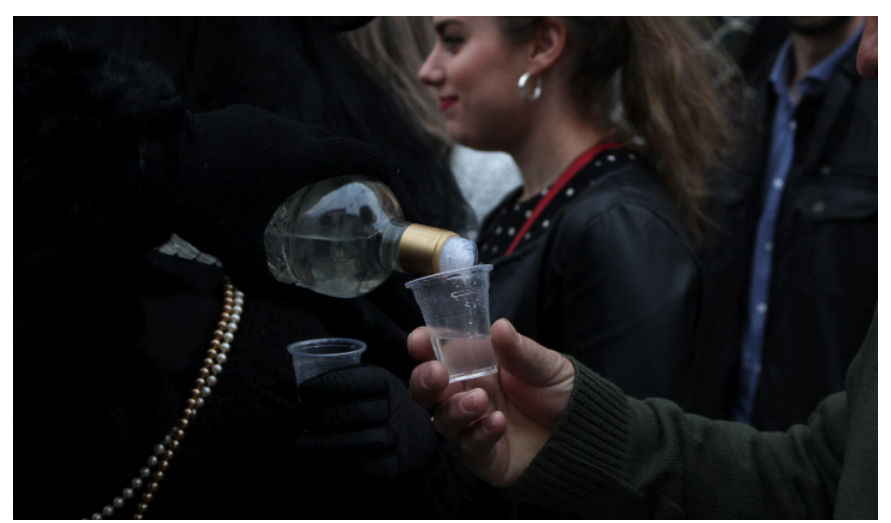

"Viuda del entornao" (máscara típica del Domingo de Piñata) sirve anís a un vecino del pueblo | fotos Azahara Lozano Dorado

gido en el Atlas del Patrimonio Inmaterial de Andalucía del IAPH (2010). El carnaval dura una semana y media, comenzando el Jueves lardero y finalizando el Domingo de Piñata, día que pudimos asistir al evento disfrutando de primera mano del conjunto de expresiones culturales junto a los protagonistas del ritual y desde una mirada antropológica.

A la actividad se sumaron 16 asistentes, mayoritariamente estudiantes de antropología y personas socias de ASANA. El primer destino del grupo fue el casco histórico del pueblo, concretamente la calle Carrera y la plaza María la Blanca. Allí las personas participantes entablaron conversaciones con el vecindario del pueblo, obteniendo múltiples testimonios valederos para el objetivo de recopilación etnográfica. Gracias a la hospitalidad de algunos vecinos y vecinas, participantes de la acti- vidad pudieron entrar en casas particulares para disfrazarse de "máscaras", disfraces tradicionales de la fiesta, pudiendo conocer desde dentro las percepciones, emociones y vivencias de los agentes locales.

A partir de las 16:00 comienzan a transitar grupos de "máscaras", vecinos y vecinas y agrupaciones musicales, mientras paulatinamente se instalan puestos en los que se ofertan anís y "entornaos", unas empanadas originarias de la localidad elaboradas en las panaderías del pueblo en los días previos. A las 17:30 se produce "la rompía de piñata", esto es, las últimas exhibiciones de actividades musicales de murgas y chirigotas. Coinciden en el espacio máscaras, vecinos y vecinas, chirigotas y pasacalles, en compañía de su respectiva batucada y carroza. Así, pudimos observar que las letras de las agrupaciones hacían referencia a eventos y "personajes" del pueblo, tal como comentó una de las personas que formó parte del conjunto de informantes previo a la actividad. De esta forma, informantes partícipes de agrupaciones del carnaval nos trasladaron la función de las letras, cuyo objetivo es el de hacer públicas las opiniones de la población respecto a, tanto la alcaldía y su gobernanza, como sus habitantes y "cotilleos". En múltiples ocasiones serán los vecinos y vecinas quienes acudirán a las agrupaciones para solicitar la inclusión de temas de interés en sus letras. Posteriormente, tiene lugar la entrega de premios de los diferentes concursos llevados a cabo durante la semana y, para finalizar, se realiza "la quema del entornao" en el recinto ferial, que consiste en calcinar un entornao de cartón y papel de grandes dimensiones.

La actividad resultó exitosa desde el objetivo que nos marcamos: la experiencia directa de los participantes en los aspectos culturales y simbólicos de la festividad a través de la convivencia con los agentes locales. Asimismo, podemos afirmar que, el ejercicio reflexivo en torno a la pluralidad de significaciones que conforman el Carnaval de Fuentes ha sido alcanzado en tanto que objetivo. La percepción del trabajo realizado por parte de quienes participaron es positiva, lo cual se acoge con agradecimiento. También, queremos reconocer la labor de documentación realizada durante la festividad, la cual será devuelta a través de "Caleidoscopio" para poder alcanzar el ejercicio de divulgación. 